\title{
Analysis of the Relative Price in China's Energy Market for Reducing the Emissions from Consumption
}

\author{
Shumin Jiang ${ }^{1,2, *}$, Jingtao Guo ${ }^{2}$, Chen Yang ${ }^{2}$, Zhanwen Ding ${ }^{1,2}$ and Lixin Tian ${ }^{1,2}$ \\ 1 Center for Energy Development and Environment Protection strategy Research, Jiangsu University, \\ Zhenjiang 212013, China; dgzw@ujs.edu.cn (Z.D.); tianlx@ujs.edu.cn (L.T.) \\ 2 Faculty of Science, Jiangsu University, Zhenjiang 212013, China; 18252586560@163.com (J.G.); \\ yangchen11216@163.com (C.Y.) \\ * Correspondence: jsm@ujs.edu.cn
}

Academic Editor: Javier Contreras

Received: 2 March 2017; Accepted: 4 May 2017; Published: 9 May 2017

\begin{abstract}
As a developing country, extensive carbon and sulfur emissions are associated with China's rapid social and economic development. Chief among them are the emissions from coal and oil consumption. This paper focuses on the demand side, attempting to regulate the range of relative price of oil to coal at the consumption level. Through the adjustment of the relative price, the goal of reducing the emissions of carbon and sulfur could be achieved in the market of energy consumption. Data regression is applied to investigate the functional relationship between emissions and energy prices. The results indicate that when the coal price is less than 300 , the higher relative price leads to less carbon and sulfur emissions; when the coal price is more than 300 and less than 500, there exists an optimal relative price which has the least carbon emissions, and this value is not more than 11.5; when the coal price is more than 500 , the smaller relative price is beneficial to decline carbon and sulfur emissions. The changed trend of relative price-sulfur emissions is very similar to relative price-carbon emissions. Compared to the present energy situation in China, the relative price of oil to coal still need to be reduced especially when coal price is more than 500 .
\end{abstract}

Keywords: relative price; regression; grey correlation degree; carbon emissions

\section{Introduction}

Global primary energy consumption has increased with a low growth rate in recent years. In 2015, the world's primary energy consumption only rose $1.0 \%$, which dropped to the lowest value in recent 20 years. The main contributor was the reduction of China's coal consumption [1]. According to the National Bureau of Statistics, coal has accounted for about $70 \%$ of the total primary energy consumption in China since 1978. The large amount of coal resources widely used in steel industry and thermal power plants promote the economic growth of China, and they are nearly in line in the past 30 years [2]. Meanwhile, the high dependence on coal combustion brings excessive carbon emissions. Over $80 \%$ of carbon emissions in China are caused by coal combustion [3]. In 2012, 83\% of energy-based emissions were from coal, which hold more than half of the total. Fourteen percent were from oil, and only $3 \%$ from natural gas [4]. The excessive carbon emissions cause a noticeable effect on the global climate, such as global warming, sea level rise, and GDP reduction. The Intergovernmental Panel on Climate Change (IPCC) predicted that the global surface temperature will increase by $4.8^{\circ} \mathrm{C}$ and sea levels by $0.82 \mathrm{~m}$ by the year 2100 [5]. In addition, carbon emissions have been estimated to cause a loss of $5 \%$ to $20 \%$ annual global GDP [6]. Reducing carbon emissions is urgent for all countries. At the Copenhagen conference, China promised to decrease $40-50 \%$ of its carbon intensity by 2020 
with respect to 2005 levels. Furthermore, this target was listed as a compulsory requirement of the long-term National Economic Development Plan.

The National Bureau of Statistics noted that from 2013 to 2015, the proportion of Chinese coal consumption was $67 \%, 66 \%$, and $64 \%$ respectively. That is to say, the coal consumption proportion is decreasing. Simultaneously, the oil consumption showed an increasing tendency at the same period, which led China to be the biggest import country in 2015 [1]. The increasing consumption of oil brought a great number of sulfur emissions, which degraded the air quality and damaged public health [7], leading to acid deposition, photo-chemical smog, heavy haze, etc. [8-11]. Especially, PM2.5 has a great impact on human health, the global climate, and regional visibility, causing increasing cases of lung disease [12-14]. Thus, sulfur emissions and carbon emissions cannot be ignored. It is an urgent and imperative issue that the government must face.

How to effectively reduce carbon and sulfur emissions? Some measures, such as industrial structure adjustment, energy efficiency improvement, and technological progress, have been put forward to reduce energy consumption and carbon and sulfur emissions steadily. Technological progress is often argued as a key approach for energy conservation and emission reduction. However, excepting a technological approach that can increase supply, China also needs to find a way to decrease demand [15]. Energy price, the key indicator of energy market in China, contains plenty of market information on the supply-demand relationship, the imports and exports, and government policies, etc., and is currently regarded as a core and key element for energy-saving and emissions abatement $[16,17]$. In fact, the Chinese government has chosen energy price as the critical role in economic and social development, and regulated it at a low level for a long time [18]. In fact, not just China, but many other countries regard energy price as an important regulating measure in the market. These countries generally orient energy price focusing on raising price to disfavored production or lowering consumer price to affect energy consumption for users [19].

Although many studies have researched the key role of energy price and its impact on environment in China, the results vary considerably due to different points of view and perspectives. This paper attempts to investigate the market-oriented energy price as a mechanism to manage its carbon and sulfur emissions in the context of the coal and oil market at the consumption-level. Especially, we firstly chose a database of daily energy price and consumption in China from January 2014 to December 2015, and confirmed the functional relationship between energy price and related carbon and sulfur emissions. Then, the range of relative price of oil to coal was estimated for the purpose of carbon and sulfur abatement.

We used energy price of oil and coal in the period 2014-2015 in China as our research context and scope of study for two reasons:

Firstly, energy price is often considered to have an impact (positive or negative) on energy consumption [20-22]. Further, Li and Lin [23] confirmed the vital role of energy price that affected energy consumption and environment quality. Therefore, energy price provides us with a quantitative instrument to study emissions reduction.

Second, coal and oil hold high proportion in total energy consumption, and play a critical role in carbon and sulfur emissions. In recent years, the Chinese government has announced a series of coal and oil reform policies. In 2013, the double-track coal pricing system was abolished by the Chinese government for the market coal and the contact coal. In 2014, several coal-related fees, including coal price-regulating and environmental-compensation fund, have been canceled. Oil regulation rules were performed in 2013. The government adjusts the domestic oil price according to international oil price every ten working days.

The aim of the government's regulatory strategies are to save energy and reduce emissions via price adjustment. This means that energy price reform is the most urgent energy issue in China, and energy price should be a good starting point to study emission problems. Some researchers pointed out that government regulation keeping domestic energy price at a low level led to energy price distortions, which could result in wasteful energy consumption and environmental 
deterioration [24-27]. The distorted energy price containing lots of information of government policy lost the feature of market at the product-level. This paper studies how variation trend of energy consumer price affects carbon and sulfur emissions at the consumption-level. Consumer price is the end-use price after government regulation. It is the synthesis of actual price including taxes, surcharges, rebates, and so on. The research at the level of consumption guarantees that results in this paper contain the influence of government regulation. The main contributions of this paper to the literature are as follows: firstly, consumer price of coal and oil, the daily consumption quantity of coal and oil, and related carbon and sulfur emissions during 2014-2015 are captured; second, our investigation extends previous study by analyzing the possible correlation between energy price and carbon/sulfur emissions; third, we get the optimal relative price of oil to coal in different price ranges of coal at the consumption-level, and policy implications for environment improvement are suggested.

The remainder of this paper is organized as follows. Section 2 presents a literature review. Section 3 briefly introduces the relevant theoretical approach and processes data. In Section 4 , we carry out a regression analysis of the model and analyze the experimental results. Section 5 focuses on the conclusion, presents some policy implications, and points out the limitations in this paper.

\section{Literature}

Prior research that studied the influence of energy price on carbon and sulfur emissions were related to two parts. One was the relationship between energy price and energy consumption, and another was the causal relationship between energy consumption and carbon/sulfur emissions.

Many studies suggested that the total energy consumed and fossil fuel used (coal and oil) had positive causal relationships with carbon emissions. These studies were conducted for Pakistan [28], India [29], the Middle East and North Africa [30,31], India and China [32], the Commonwealth of Independent States [33], Europe [34-37], and the United States [38,39]. However, some studies concluded different results suggesting that the total energy consumption was found to barely have a relationship with carbon emissions. In addition, other studies verified that such relationships were dependent on circumstances. Khan et al. [40] showed in their study the different causal relationships in different countries. In several groups of countries, there was no relationship between energy consumption and carbon emissions [41,42]. The relationship between energy consumption and carbon emissions varied in different countries because of different national conditions, geographic positions, and energy departments. In China, the positive relationship between energy consumption and carbon emissions has been confirmed in many studies [43-48]. Wang et al. [43] indicated the existence of a bidirectional positive causality between energy consumption and carbon emissions in the period 1995-2012. Hu et al. [46] examined the impact of energy consumption on concomitant air emissions during 2000-2011 and showed that China's energy consumption led to the increasing impact on emissions. In earlier empirical studies by Chang [45], Li et al. [48], and Zhang et al. [47], the causality between energy consumption and related carbon emissions in the periods of 1981-2006, 1985-2007, and 1978-2007, respectively, and demonstrated that energy consumption and carbon emissions indicated bidirectional causality with a feedback effect.

Research on the causal relationship between energy price and energy consumption found both negative and positive relationships. The negative own-price elasticity for coal and oil was found by Bloch et al. [49] in 2015, which implied that the consumption of coal and oil fell with rising price. Yuan et al. [20] concluded that the higher price decreased energy consumption in Chinese industrial and residential sectors in the long run. Liu and Zhao [50] found that increasing energy price restrained residential energy consumption in China from 1993-2011. Many studies in China verified that, basically, energy price negatively caused carbon emissions. Haugom et al. [51] showed that yearly changes of oil price in the range of $2-12 \%$ would likely cause substantial structural changes in the oil demand. Zhang and $\mathrm{Xu}$ [22] and Hang and Tu [52] concluded that the effects of energy prices on energy consumption varied by sector, region, and energy source in China. 
Thus, the change of coal or oil price will not only affect their own energy consumption, but also influence the consumption of the other alternative energy through the choice of consumers. At the same time, the dynamic pricing of coal and oil is bound to appear and the relative price can be obtained. The relative price could reflect the relationship between coal consumption and oil consumption by rule and line rather than absolute price. The optimization of relative prices could be explored to optimize energy market structure and reduce the emissions of carbon and sulfur. In brief, energy price greatly influences energy consumption, and both of them have an impact on carbon and sulfur emissions. What is more, the relative price of oil to coal, as an important indicator in energy market, is also relative to carbon and sulfur emissions. Studying the characteristics of the relative price is helpful to understand the current energy market and reveal the impact of relative price change on environmental quality.

\section{Methodology and Data}

\subsection{Methodology}

In time series modeling, economic theory is applied to analyze the relationship among variables. The inverse demand function is adopted in this paper. It is specified as follows:

$$
D_{i}=f\left(P_{i}\right)
$$

where $P_{i}$ and $D_{i}$ denote the energy price and consumption quantity of the $i$-th fuel. Using energy consumption data and the method proposed by IPCC [53], we calculate carbon and sulfur emissions caused by energy consumption.

$$
\begin{aligned}
& W_{1}=\sum_{i} D_{i} \times C O_{2} E F_{i} \\
& W_{2}=\sum_{i} D_{i} \times S O_{2} E F_{i}
\end{aligned}
$$

where $W_{1}, W_{2}$ represent the amount of carbon dioxide emissions and sulfur dioxide emissions generated by energy consumption; $\mathrm{CO}_{2} E F_{i}, \mathrm{SO}_{2} E F_{i}$ indicate $\mathrm{CO}_{2}$ emission coefficient and $\mathrm{SO}_{2}$ emission coefficients of the $i$-th fuel, respectively.

As an invisible hand in the market, energy price is an important indicator that reflects the market fluctuation and influences environmental quality. Many studies have confirmed that the change of energy price not only affects energy consumption but also has an impact on concomitant energy consumption-carbon and sulfur emissions. Taking Equation (1) into Equations (2) and (3), we get

$$
\begin{aligned}
& W_{1}=f_{1}\left(P_{i}\right) \\
& W_{2}=f_{2}\left(P_{i}\right)
\end{aligned}
$$

In this paper, it is assumed that energy price will affect energy consumption and related carbon and sulfur emissions. With the change of the energy situation, it is very necessary to investigate the relationship between energy price and carbon and sulfur emissions in recent years at the consumption level. The analysis and prediction in the paper are beneficial to risk management and provide policy suggestions for the government.

\subsection{Grey Correlation Analysis}

Grey correlation analysis (GCA), proposed by Deng in 1982 [54], is an important part of grey system theory (GST) and can be applied to determine the relational degree through weight value, which is correctly assigned to the feature of indicators. GCA is used to evaluate the relational degree between data sequences of two features based on the similarity of geometric tendency of sequence time series [55]. In the GCA process, time series data is not needed to satisfy a normal distribution, and 
there is no necessity to test the statistical significance of the GCA result. The higher the relative degree between two time series, the higher the value we give to the relative degree of the corresponding data sequences [56,57]. In the current research of economic time series, Jia et al. (2015) studied the multivariate dynamic correlation of oil prices using an optimal wavelet analysis based on GCA [58].

The following give the detailed method of calculating the grey correlation degree. If the data series of a system are

$$
\left\{\begin{array}{l}
X_{0}=\left(x_{0}(1), x_{0}(2), \ldots ., x_{0}(n)\right) \\
X_{1}=\left(x_{1}(1), x_{1}(2), \ldots ., x_{1}(n)\right) \\
\ldots \\
X_{m}=\left(x_{m}(1), x_{m}(2), \ldots ., x_{m}(n)\right)
\end{array},\right.
$$

The grey correlation degree of $X_{0}$ and $X_{i}$ on the point of $k$ is $\gamma\left(x_{0}(k), x_{i}(k)\right)$

$$
\gamma\left(x_{0}(k), x_{i}(k)\right)=\frac{\min _{i} \min _{k}\left|x_{0}(k)-x_{i}(k)\right|+\xi \max _{i} \max _{k}\left|x_{0}(k)-x_{i}(k)\right|}{\left|x_{0}(k)-x_{i}(k)\right|+\xi \max _{i} \max _{k}\left|x_{0}(k)-x_{i}(k)\right|}
$$

and

$$
\gamma\left(X_{0}, X_{i}\right)=\frac{1}{n} \sum_{k=1}^{n} \gamma\left(x_{0}(k), x_{i}(k)\right)
$$

where $\xi \in(0,1)$ is usually given the value of 0.5 . Deng [54] found that 0.5 is the optimum value of $\xi$, because this value provides moderate distinguishing effects and good stability.

\subsection{Data}

This paper aims to explore the relationship between energy price and carbon and sulfur emissions at the consumption level. Additionally, the Chinese consumer price and the consumption of coal and oil during 2014-2015 are collected.

Data in this paper are taken from the International Gas Network and China Coal Market Online (CCTD). The data of oil consumption and oil price are primary from the National Development and Reform Commission (NDRC). Therein, the coal consumption data are monthly and the coal price data are daily. For unitive analysis, the final data of coal price are the weighted average of month. The unit of oil consumption is converted into the uniform unit of billion tons of standard coal.

The coefficients of carbon emissions will follow the value $0.68 \mathrm{~T} / \mathrm{tec}$ and $0.585 \mathrm{~T} / \mathrm{tec}$ of coal and oil, respectively. The coefficients of sulfur emissions will follow the value $0.024 \mathrm{~T} /$ tec and $0.04 \mathrm{~T} / \mathrm{tec}$ of coal and oil. These data are from the Energy Research Institute of the National Development and Reform Commission.

\section{Calculation}

Regression analysis is a methodology that allows a functional relationship among dependent variables and independent variables to be found. It includes two forms: linear regression and nonlinear regression. The relationships between energy price and carbon and sulfur emissions are believed to be nonlinear because the linear form may cause greater deviation from real data. On the contrary, polynomial regression is a special form of nonlinear regression, and shows promising results because of the reasonable accuracy and relatively simple implementation compared with other methods.

The functional relations between energy price and carbon/sulfur emissions at the consumption level established in Section 3 are estimated to use polynomial regression by fitting with the method of least squares. We assumed that $P_{1}$ and $P_{2}$ are consumer price of coal and oil as predictor variables, $W_{1}$ and $W_{2}$ are carbon and sulfur emissions caused by the consumption of coal and oil as the respond variables; the consumption of coal and oil are denoted as $D_{1}$ and $D_{2}$, respectively. The simulated results are shown as follows: 


$$
\begin{gathered}
W_{1}=55,638.9008+40.8897 P_{1}-21.3877 P_{2}-0.2912 P_{1}^{2}+0.046 P_{1} P_{2}+0.0003855 P_{2}^{2} \\
W_{2}=2006.944+1.8307 P_{1}-0.7489 P_{2}-0.01125 P_{1}^{2}+0.001703 P_{1} P_{2}+0.000009122 P_{2}^{2}
\end{gathered}
$$

Then, grey correlation analysis (GCA) was applied as a verification to explore the correlation between the price and emissions data. The processed price data of coal and oil are taken into Equation (8). The results show that the correlation coefficients between coal price and carbon/sulfur emissions are 0.6091 and 0.6049 . The correlation coefficients between oil price and carbon/sulfur emissions are 0.7943 and 0.7814 , respectively. This indicates that a stronger correlation exists between consumer price of coal and oil and related carbon and sulfur emissions. The conclusion further illustrates that carbon and sulfur emissions could be expressed as a function of energy price.

In order to further analyze the rationality of regression, the standardized residual and standard deviation distribution of carbon emissions and sulfur emissions in Equations (9) and (10) are shown in Figures 1 and 2.

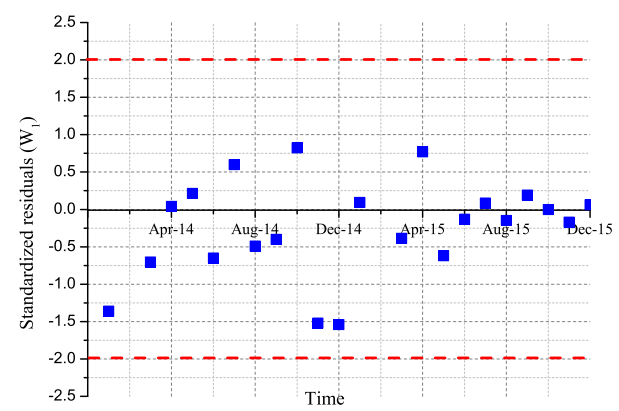

(a)

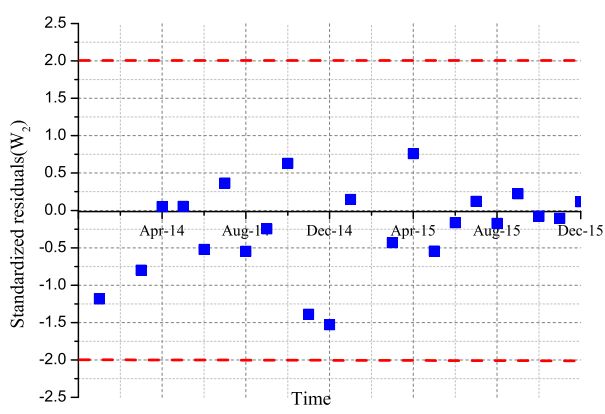

(b)

Figure 1. (a) The standardized residual of $W_{1} ;$ (b) The standardized residual of $W_{2}$.

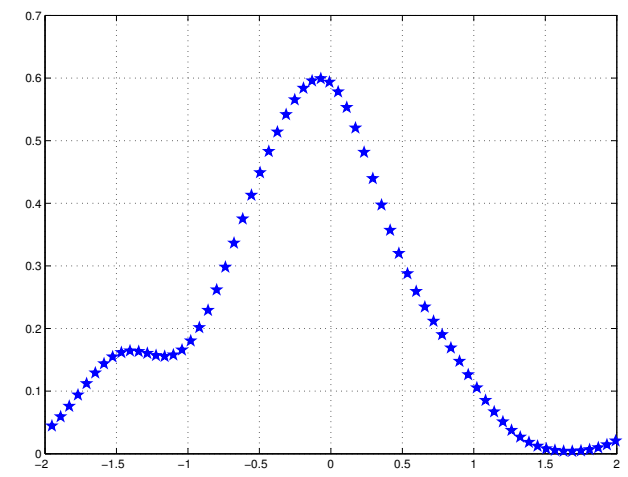

(a)

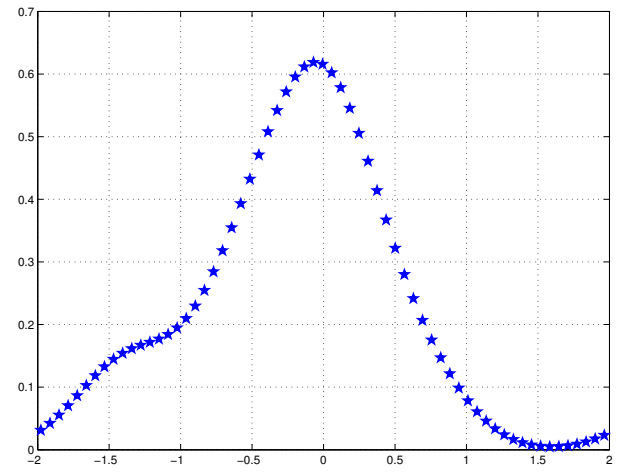

(b)

Figure 2. (a) The standard deviation distribution of $W_{1}$ in Equation (9); (b) The standard deviation distribution of $W_{2}$ in Equation (10).

In Figure 1, the values of the standardized residual are mainly distributed above and below the $X$-axis evenly. The sum of residual errors of selected Equations (9) and (10) are relatively small. In order to analyze the standardized residual further, Figure 2 presents the standard deviation distribution of carbon emissions and sulfur emissions, and it approximates a normal distribution. 


\section{Results and Discussion}

This paper considers the role of trending relative price of oil to coal and studies the impact on carbon and sulfur emissions. Taking the relative price of oil to coal as $\alpha$, Equations (4) and (5) can be rewritten as

$$
W_{i}=f_{i}\left(P_{1}, \alpha P_{1}\right), i=1,2
$$

This equation is interpreted as a plane in a three-dimensional graph of $W_{i}$ in the vertical direction vs. $P_{1}$ and $\alpha$ defining a base plane. We chose energy consumer price of coal price in the range of $(0,800)(Y u a n / t c e)$, which is the possible minimum and maximum of coal price in current market condition.

When the coal price varies from 0 to 800 (Yuan/tce), the impact of gradual increase in coal price on $\mathrm{CO}_{2}$ and $\mathrm{SO}_{2}$ are illustrated in Figure 3a,b. It shows that $\mathrm{CO}_{2}$ and $\mathrm{SO}_{2}$ are affected by coal price changes, and mainly present two stages in variation tendency. In the first stage, coal price with a low value exhibits an inapparent variation of $\mathrm{CO}_{2}$ and $\mathrm{SO}_{2}$ emissions, regardless of the range of relative price. In the second stage with a higher consumer price of coal, $\mathrm{CO}_{2}$ and $\mathrm{SO}_{2}$ emissions generally increase. Overall, $\mathrm{CO}_{2}$ and $\mathrm{SO}_{2}$ emissions show a similar variation tendency. Particularly, the minimum quantities of $\mathrm{CO}_{2}$ and $\mathrm{SO}_{2}$ emissions exist within a certain price range.

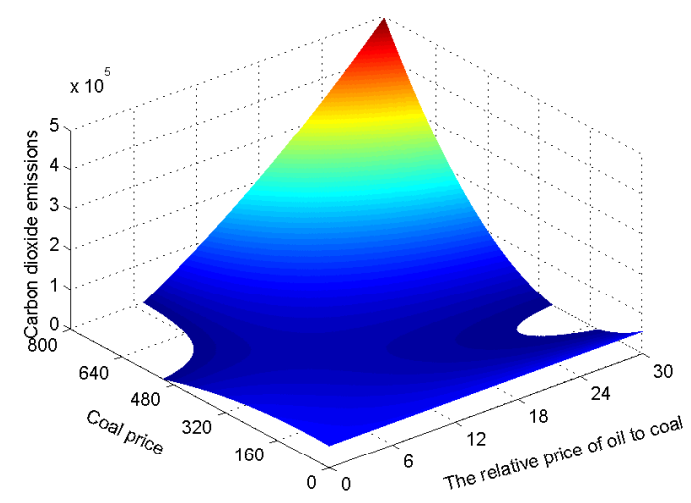

(a)

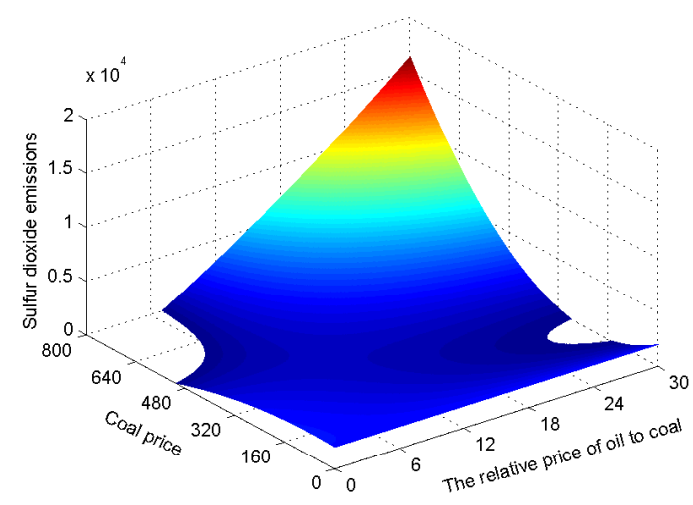

(b)

Figure 3. (a) The three-dimensional graph of $W_{1}, P_{1}$, and $\alpha$; (b) The three-dimensional graph of $W_{2}$, $P_{1}$, and $\alpha$.

In order to analyze the trend concretely, coal price range is broke into three parts: 0-300 (Yuan/tce), 300-500 (Yuan/tce), 500-800 (Yuan/tce). We focus the discussion on coal price in a range from 300 (Yuan/tce) to 500 (Yuan/tce) because the current consumer price of coal remains in this interval as a whole. The evolution trends of $\mathrm{CO}_{2}$ and $\mathrm{SO}_{2}$ emissions with coal price between 0-300 (Yuan/tce) and 500-800 (Yuan/tce) are worth studying because they represent the probable situation in the prospective energy market. The data from the Annual Report on Coal Industry in China 2015 showed that the price of market coal before 2008 was less than 300 (Yuan/tce). The investigation on the lower coal price enriches market feature and enhances understanding of the relationship between relative price and $\mathrm{CO}_{2}$ and $\mathrm{SO}_{2}$ emissions. As for government regulation on energy price (especially fossil fuel), the removal of fossil fuel subsidy would lead to higher energy prices, which is well within the range from 500 (Yuan/tce) to 800 (Yuan/tce) [59]. For ease of observation and comparison, the consumer price of coal and relative price of oil to coal during 2014-2015 are shown in Figure 4. 


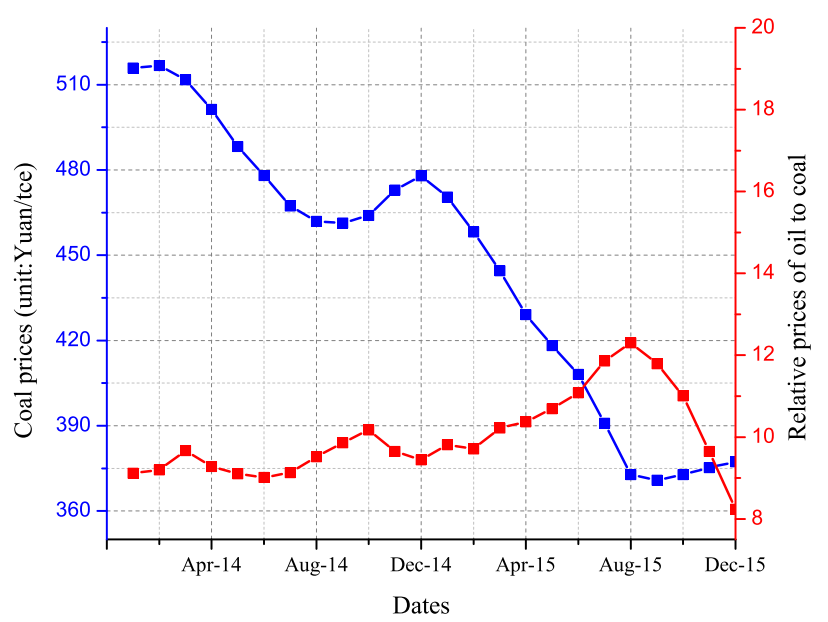

Figure 4. The three-dimensional graph of $W_{1}, P_{1}$, and $\alpha$.

According to Figure 4, monthly data of coal price mainly remains in a range from 300-500 (Yuan/tce), and the relative price of oil to coal is not less than 8. In the following discussion, coal prices in different ranges are selected, and then cross-sectional views of $\mathrm{CO}_{2}$ and $\mathrm{SO}_{2}$ emissions with relative price changes are presented. Because the relative price is tightly related to consumer price of oil, which suffers from the influence of the international oil market to some extent. There is no limit to the range of the relative price of oil to coal. Thus, this paper investigates the curve of $\mathrm{CO}_{2}$ and $\mathrm{SO}_{2}$ affected by relative price in different ranges of coal price.

When the coal price varies between 300-500 (Yuan/tce), the cross-sectional views of $\mathrm{CO}_{2}$ and $\mathrm{SO}_{2}$ emissions are simulated in Figure 5. We can see that both $\mathrm{CO}_{2}$ and $\mathrm{SO}_{2}$ emissions caused by coal and oil consumption are fluctuant and present different characteristic curves under different values of coal price. The $\mathrm{SO}_{2}$ emissions have a similar evolution process with the $\mathrm{CO}_{2}$ emission trend. Moreover, the relative price of oil to coal significantly affects $\mathrm{CO}_{2}$ and $\mathrm{SO}_{2}$ emissions.

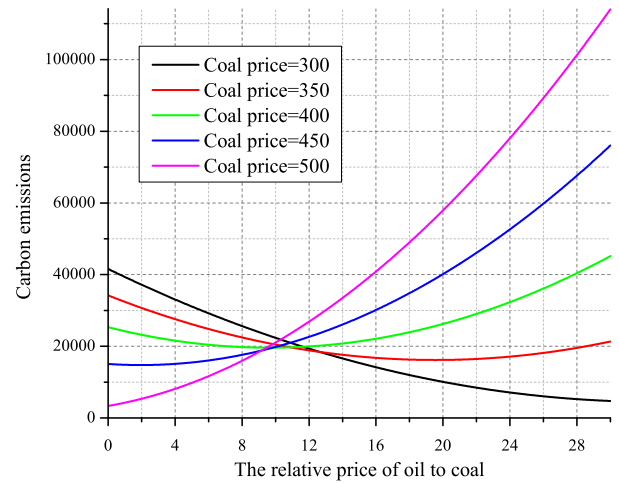

(a)

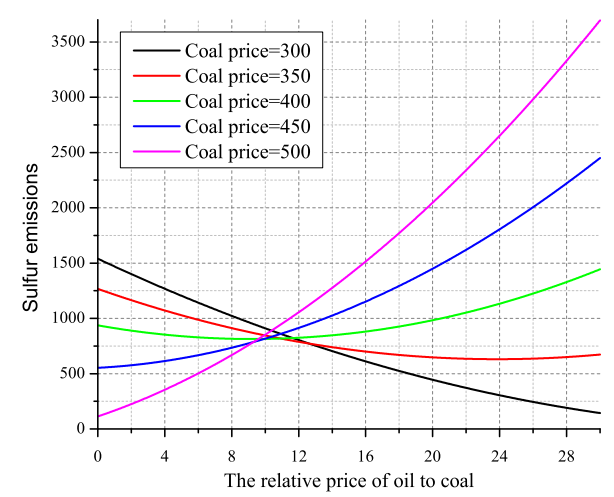

(b)

Figure 5. (a) The cross-sectional views of $W_{1}$ with coal price $P_{1}$ between $300-500$; (b) The cross-sectional views of $W_{2}$ with coal price $P_{1}$ between 300-500.

Combining Figure 5 with specific calculation, when the relative price is less than $9, \mathrm{CO}_{2}$ and $\mathrm{SO}_{2}$ emissions decrease with the increase of coal consumer price. Meanwhile, when the ratio is greater than 14, the nearly reverse trend of carbon and sulfur emissions are presented obviously. Further, coal price in a range from 300 (Yuan/tce) to 500 (Yuan/tce) will adjust the value of relative price at the 
point of intersection, which moves to a lower value of relative price. Through numerical calculation, the optimal relative price of oil to coal is around 12.5. Thus, the smaller the values the relative price and coal price have, the lesser emissions emit of amounts the $\mathrm{CO}_{2}$ and $\mathrm{SO}_{2}$.

When the coal price is in the range of 0-300 (Yuan/tce) and 500-800 (Yuan/tce), the cross-sectional views of emitted $\mathrm{CO}_{2}$ and $\mathrm{SO}_{2}$ emissions are described in Figures 6 and 7, respectively.

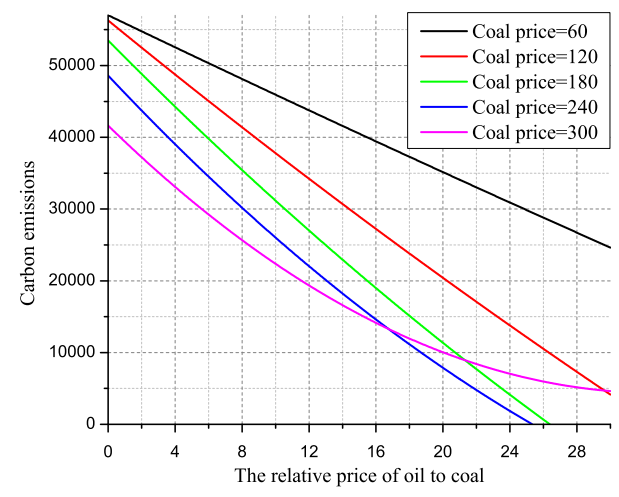

(a)

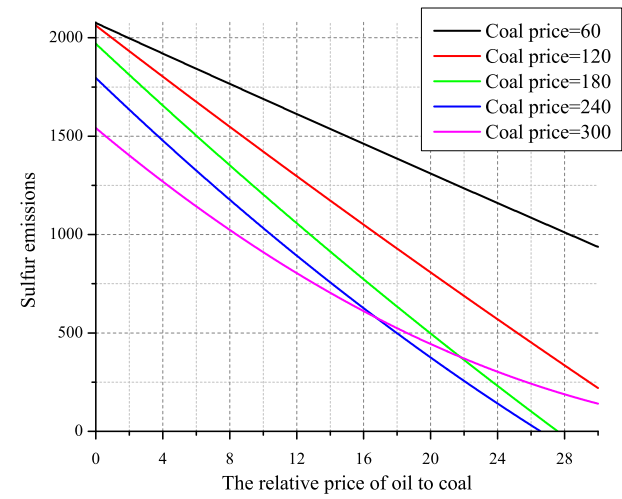

(b)

Figure 6. (a) Cross-sectional views of $W_{1}$ with coal price $P_{1}$ between 0-300; (b) Cross-sectional views of $W_{2}$ with coal price $P_{1}$ between $0-300$.

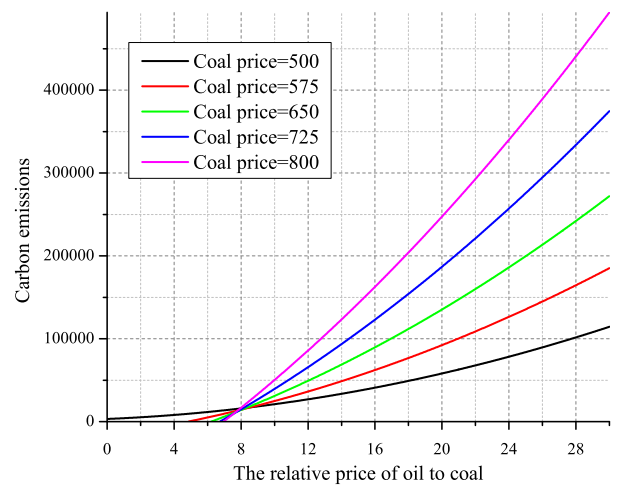

(a)

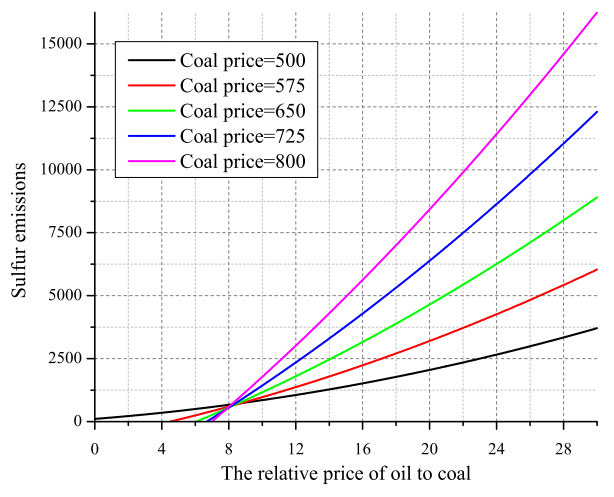

(b)

Figure 7. (a) Cross-sectional views of $W_{1}$ with coal price $P_{1}$ between 500-800; (b) Cross-sectional views of $W_{2}$ with coal price $P_{1}$ between $500-800$.

According to Figure $6 \mathrm{a}, \mathrm{b}$, with relative price increases, $\mathrm{CO}_{2}$ and $\mathrm{SO}_{2}$ emissions have a similar mitigate. In particular, when the coal price is 200 (Yuan/tce), the pace of decline rate accelerated from the previous coal price that is less than 200. Meanwhile, when the coal price is 300 (Yuan/tce), $\mathrm{CO}_{2}$ and $\mathrm{SO}_{2}$ emissions have an obvious slowdown trend with a relative price that is more than 16 . Therefore, when consumer price of coal ranges from 0 to 300 (Yuan/tce), the smaller coal price and relative price goes against the abatement of $\mathrm{CO}_{2}$ and $\mathrm{SO}_{2}$ emissions, but the impact on $\mathrm{CO}_{2}$ and $\mathrm{SO}_{2}$ increase is not obvious. The result indicates that coal price lower than 300 is far more favorable to decrease $\mathrm{CO}_{2}$ and $\mathrm{SO}_{2}$ emissions.

In Figure 7, the changed trends of carbon and sulfur emissions are completely different from the variation trends in the range of coal price between 0-300 (Yuan/tce). When the coal price is from 500 (Yuan/tce) to 800 (Yuan/tce), the evolution of carbon emissions and sulfur emissions show a similar increasing trend regardless of the value of relative price. Further, greater values of coal price show 
faster growth ratio. Thus, the reduction in both consumer price of coal during 500-800 (Yuan/tce) and relative price is beneficial to decrease $\mathrm{CO}_{2}$ and $\mathrm{SO}_{2}$ emissions. Compared with variation trend during 0-300 (Yuan/tce), the decrease of relative price becomes more pressing and urgent in the market of energy consumption.

\section{Conclusions}

The high speed of economic growth requires large amounts of energy input. The selection of different energy sources are closely related to the environment quality, which is an issue of long concern by the public and government. As the energy market rises or falls, the emissions of $\mathrm{CO}_{2}$ and $\mathrm{SO}_{2}$ are unstable and continuously changing. Energy price is influenced by energy demand and supply, and has a significant impact on the $\mathrm{CO}_{2}$ and $\mathrm{SO}_{2}$ emissions. This research investigated the impact of relative consumer price of oil and coal on $\mathrm{CO}_{2}$ and $\mathrm{SO}_{2}$ emissions at the consumption level during 2014-2015 using regression analysis.

For a certain coal price, a better relative price is helpful to reduce $\mathrm{CO}_{2}$ and $\mathrm{SO}_{2}$ emissions. This paper explored and obtained the optimal relative price of oil to coal when the coal price varies in different ranges. When the coal price is more than 300 (Yuan/tce) and less than 500 (Yuan/tce), the optimal relative price should be less than 11.5 to ensure the $\mathrm{CO}_{2}$ and $\mathrm{SO}_{2}$ emission reduction. Coal price less than 300 (Yuan/tce) has no special requirement on the relative price. When the coal price is more than 500 (Yuan/tce), it is very necessary to decrease the relative price to a low value.

Comparing the existing relative price with simulated optimal relative price, the existing relative prices range from 8-12.5, corresponding to average coal price from 360-510 (Yuan/tce). The current relative price is relatively reasonable in the market of energy consumption. Special attention must be paid to the coal price, which should be no more than 500 (Yuan/tce).

\subsection{Policy Implications}

The research conclusions are also significant for policy makers in China to pay attention to the findings. The consumer price of coal and oil containing government regulation contains plenty of market information. This paper studied the impact of relative price of oil to coal on related $\mathrm{CO}_{2}$ and $\mathrm{SO}_{2}$ emission at the consumption level. According to this study, some suggestions are put forward for the government to alleviate the current high $\mathrm{CO}_{2}$ and $\mathrm{SO}_{2}$ emission from the following aspects.

First, government pricing of energy is one of the policy instruments in China. In theory, energy price affects demand and supply, and is an important control measure for energy consumption and related $\mathrm{CO}_{2}$ and $\mathrm{SO}_{2}$ emissions. In this paper, grey correlation analysis verified the compact correlation between energy price and emissions. Thus, the government can adjust energy price as a powerful tool to reduce $\mathrm{CO}_{2}$ and $\mathrm{SO}_{2}$ emissions. The results provide the government with a practical and feasible foundation for market regulation.

Second, government adjustment of coal price at low-level should ensure that the relative price of oil to coal is not more than 11.5 , especially when coal price is more than 500 . Due to the dominant position held by coal and oil consumption, regulations on coal and oil price affect related $\mathrm{CO}_{2}$ and $\mathrm{SO}_{2}$ emissions, and then have a significant impact on total emissions. This paper studies the influence of the relative price of oil to coal on $\mathrm{CO}_{2}$ and $\mathrm{SO}_{2}$ emissions with different ranges of coal price. The results present different adjusting and controlling extents of relative price comprehensively, no matter what the range of coal price is.

\subsection{Limitations and Future Research Directions}

With the acceleration of urbanization, energy consumption as well as carbon and sulfur emissions grew rapidly during the period 2014-2015. Considering social stability and environmental quality, energy price in China has been processed for a long time. This study adopts a static framework to analyze the short-run effect of the relative price of oil to coal in China's coal and oil sectors. However, the government pricing of coal and relative price may also have long-term effects. Estimation 
of long-term coal price and relative price is necessary. Therefore, the future research directions are as follows: firstly, estimating the changing scale of relative price in China over a longer time; secondly, estimating the evolution trend of coal price and the related relative price of oil to coal that excludes government subsides; last but not least, estimating environmental impacts (carbon and sulfur emissions) when the coal price without government subsidies in China's different energy sectors.

Acknowledgments: Project is supported by the National Natural Science Foundation of China (Grant No. 51306072, 71690242 and 91546118) and the Senior Talent Foundation of Jiangsu University, China (Grant Nos. 09JDG073 and 15JDG083).

Author Contributions: Shumin Jiang designed this research and wrote this paper; Zhanwen Ding and Lixin Tian provided professional guidance; Jingtao Guo and Chen Yang collected all the data and translated this paper.

Conflicts of Interest: The authors declare no conflict of interest.

\section{References}

1. BP Global. BP StatistiSta Review of World Energy 2016; BP Global: London, UK, 2015.

2. Wang, C.; Chou, M.; Hsu, H.; Wang, J.; Selvaraj, S. The Efficiency Improvement by Combining HHO Gas, Coal and Oil in Boiler for Electricity Generation. Energies 2017, 10, 251.

3. Carbon Dioxide Information Analysis Center (CDIAC). Caron Dioxide Information Analysis Center; Carbon Dioxide Information Analysis Center: Oak Ridge, TN, USA, 2011.

4. International Energy Agency (IEA). Carbon Dioxide from Fuel Combustion 2014; International Energy Agency: Paris, France, 2014.

5. International Panel on Climate Change (IPCC). Intergovernmental Panel on Climate Change; International Panel on Climate Change: Geneva, Switzerland, 2014.

6. Pielke, R., Jr. Mistreatment of the economic impacts of extreme events in the Stern Review Report on the Economics of Climate Change. Glob. Environ. Chang. 2007, 17, 302-310.

7. Saikia, J.; Saikia, P.; Boruah, R.; Saikia, B.K. Ambient air quality and emission characteristics in and around a non-recovery type coke oven using high sulphur coal. Sci. Total Environ. 2015, 530-531, 304-313.

8. Qu, Y.; An, J.; He, Y.; Zheng, J. An overview of emissions of $\mathrm{SO}_{2}$ and $\mathrm{NO}_{x}$ and the long-range transport of oxidized sulfur and nitrogen pollutants in East Asia. J. Environ. Sci. 2016, 44, 13-25.

9. Huang, K.; Zhuang, G.; Xu, C.; Wang, Y.; Tang, A. The chemistry of the severe acidic precipitation in Shanghai, China. Atmos. Res. 2008, 89, 149-160.

10. Tao, M.; Chen, L.; Xiong, X.; Zhang, M.; Ma, P.; Tao, J.; Wang, Z. Formation process of the widespread extreme haze pollution over northern China in January 2013: Implications for regional air quality and climate. Atmos. Environ. 2014, 98, 417-425.

11. Wang, X.; Chen, J.; Cheng, T.; Zhang, R.; Wang, X. Particle number concentration, size distribution and chemical composition during haze and photochemical smog episodes in Shanghai. J. Environ. Sci. 2014, 26, 1894-1902.

12. Zheng, J.; Hu, M.; Peng, J.; Wu, Z.; Kumar, P.; Li, M.; Wang, Y.; Guo, S. Spatial distributions and chemical properties of PM2.5 based on 21 field campaigns at 17 sites in China. Chemosphere 2016, 159, 480-487.

13. Han, X.; Guo, Q.; Liu, C.; Strauss, H.; Yang, J.; Hu, J.; Wei, R.; Tian, L.; Kong, J.; Peters, M. Effect of the pollution control measures on PM2.5 during the 2015 China Victory Day Parade: Implication from water-soluble ions and sulfur isotope. Environ. Pollut. 2016, 218, 230-241.

14. Zhang, Y.; Huang, W.; Cai, T.; Fang, D.; Wang, Y.; Song, J.; Hu, M.; Zhang, Y. Concentrations and chemical compositions of fine particles (PM2.5) during haze and non-haze days in Beijing. Atmos. Res. 2016, 174-175, 62-69.

15. Voinov, A.; Filatova, T. Pricing strategies in inelastic energy markets: Can we use less if we can't extract more? Front. Earth Sci. 2014, 8, 3-17.

16. Zhao, L.; Zhang, X.; Wang, S.; Xu, S. The effects of oil price shocks on output and inflation in China. Energy Econ. 2016, 53, 101-110.

17. Ling-yun, H.; Yan, L. Characteristics of China's coal, oil and electricity price and its regulation effect on entity economy. Proc. Earth Planet. Sci. 2009, 1, 1627-1634.

18. Ouyang, X.; Sun, C. Energy savings potential in China's industrial sector: From the perspectives of factor price distortion and allocative inefficiency. Energy Econ. 2015, 48, 117-126. 
19. Sovacool, B.K. Reviewing, Reforming, and Rethinking Global Energy Subsidies: Towards a Political Economy Research Agenda. Ecol. Econ. 2017, 135, 150-163.

20. Yuan, C.; Liu, S.; Wu, J. The relationship among energy prices and energy consumption in China. Energy Policy 2010, 38, 197-207.

21. Nesbakken, R. Price sensitivity of residential energy consumption in Norway. Energy Econ. 1998, 21, 493-515.

22. Zhang, C.; Xu, J. Retesting the causality between energy consumption and GDP in China: Evidence from sectoral and regional analyses using dynamic panel data. Energy Econ. 2012, 34, 1782-1789.

23. Li, K.; Lin, B. Impacts of urbanization and industrialization on energy consumption $/ \mathrm{CO}_{2}$ emissions: Does the level of development matter? Renew. Sustain. Energy Rev. 2015, 52, 1107-1122.

24. Saboohi, Y. An evaluation of the impact of reducing energy subsidies on living expenses of households. Energy Policy 2001, 29, 245-252.

25. Riedy, C.; Diesendorf, M. Financial subsidies to the Australian fossil fuel industry. Energy Policy 2003, 31, 125-137.

26. Qiang, W.; Qiu, H.N.; Kuang, Y. Market-driven energy pricing necessary to ensure China's power supply. Energy Policy 2009, 37, 2498-2504.

27. Nwachukwu, M.U.; Chike, H. Fuel subsidy in Nigeria: Fact or fallacy. Fuel Energy Abstr. 2011, 36, $2796-2801$.

28. Mumtaz, R.; Zaman, K.; Sajjad, F.; Lodhi, M.S.; Irfan, M.; Khan, I.; Naseem, I. Retraction notice to "Modeling the causal relationship between energy and growth factors: Journey towards sustainable development" [Renewable Energy 63 (2014) 353-361]. Renew. Energy 2015, 76, 805.

29. Mirza, F.M.; Kanwal, A. Energy consumption, carbon emissions and economic growth in Pakistan: Dynamic causality analysis. Renew. Sustain. Energy Rev. 2017, 72, 1233-1240.

30. Bekhet, H.A.; Matar, A.; Yasmin, T. $\mathrm{CO}_{2}$ emissions, energy consumption, economic growth, and financial development in GCC countries: Dynamic simultaneous equation models. Renew. Sustain. Energy Rev. 2017, 70, 117-132.

31. Arouri, M.E.H.; Youssef, A.B.; M'henni, H.; Rault, C. Energy consumption, economic growth and $\mathrm{CO}_{2}$ emissions in Middle East and North African countries. Energy Policy 2012, 45, 342-349.

32. Jayanthakumaran, K.; Verma, R.; Liu, Y. $\mathrm{CO}_{2}$ emissions, energy consumption, trade and income: A comparative analysis of China and India. Energy Policy 2012, 42, 450-460.

33. Apergis, N.; Payne, J.E. The emissions, energy consumption, and growth nexus: Evidence from the commonwealth of independent states. Energy Policy 2010, 38, 650-655.

34. Bölük, G.; Mert, M. Fossil \& renewable energy consumption, GHGs (greenhouse gases) and economic growth: Evidence from a panel of EU (European Union) countries. Energy 2014, 74, 439-446.

35. Hatzigeorgiou, E.; Polatidis, H.; Haralambopoulos, D. $\mathrm{CO}_{2}$ emissions, GDP and energy intensity: A multivariate cointegration and causality analysis for Greece, 1977-2007. Appl. Energy 2011, 88, 1377-1385.

36. Acaravci, A.; Ozturk, I. On the relationship between energy consumption, $\mathrm{CO}_{2}$ emissions and economic growth in Europe. Energy 2010, 35, 5412-5420.

37. Shafiei, S.; Salim, R.A. Non-renewable and renewable energy consumption and $\mathrm{CO}_{2}$ emissions in OECD countries: A comparative analysis. Energy Policy 2014, 66, 547-556.

38. Lee, S.; Chong, W.O. Causal relationships of energy consumption, price, and $\mathrm{CO}_{2}$ emissions in the U.S. building sector. Resour. Conserv. Recycl. 2016, 107, 220-226.

39. Soytas, U.; Sari, R.; Ewing, B.T. Energy consumption, income, and carbon emissions in the United States. Ecol. Econ. 2007, 62, 482-489.

40. Khan, M.A.; Khan, M.Z.; Zaman, K.; Naz, L. Global estimates of energy consumption and greenhouse gas emissions. Renew. Sustain. Energy Rev. 2014, 29, 336-344.

41. Kivyiro, P.; Arminen, H. Carbon dioxide emissions, energy consumption, economic growth, and foreign direct investment: Causality analysis for Sub-Saharan Africa. Energy 2014, 74, 595-606.

42. Lean, H.H.; Smyth, R. $\mathrm{CO}_{2}$ emissions, electricity consumption and output in ASEAN. Appl. Energy 2010, 87, 1858-1864.

43. Wang, S.; Zhou, C.; Li, G.; Feng, K. $\mathrm{CO}_{2}$, economic growth, and energy consumption in China's provinces: Investigating the spatiotemporal and econometric characteristics of China's $\mathrm{CO}_{2}$ emissions. Ecol. Indic. 2016, 69, 184-195.

44. Zhang, X.P.; Cheng, X.M. Energy consumption, carbon emissions, and economic growth in China. Ecol. Econ. 2009, 68, 2706-2712. 
45. Chang, C.C. A multivariate causality test of carbon dioxide emissions, energy consumption and economic growth in China. Appl. Energy 2010, 87, 3533-3537.

46. Hu, H.; Zhang, X.H.; Lin, L.L. The interactions between China's economic growth, energy production and consumption and the related air emissions during 2000-2011. Ecol. Indic. 2014, 46, 38-51.

47. Zhang, X.H.; Zhang, R.; Wu, L.Q.; Deng, S.H.; Lin, L.L.; Yu, X.Y. The interactions among China's economic growth and its energy consumption and emissions during 1978-2007. Ecol. Indic. 2013, 24, 83-95.

48. Li, F.; Dong, S.; Li, X.; Liang, Q.; Yang, W. Energy consumption-economic growth relationship and carbon dioxide emissions in China. Energy Policy 2011, 39, 568-574.

49. Bloch, H.; Rafiq, S.; Salim, R. Economic growth with coal, oil and renewable energy consumption in China: Prospects for fuel substitution. Econ. Model. 2015, 44, 104-115.

50. Liu, Z.; Zhao, T. Contribution of price/expenditure factors of residential energy consumption in China from 1993 to 2011: A decomposition analysis. Energy Convers. Manag. 2015, 98, 401-410.

51. Haugom, E.; Mydland, Ø.; Pichler, A. Long term oil prices. Energy Econ. 2016, 58, 84-94.

52. Hang, L.; Tu, M. The impacts of energy prices on energy intensity: Evidence from China. Energy Policy 2007, 35, 2978-2988.

53. Eggleston, S.; Buendia, L.; Miwa, K.; Ngara, T.; Tanabe, K. 2006 IPCC Guidelines for National Greenhouse Gas Inventories Volume 1: General Guidance and Reporting; International Panel on Climate Change: Geneva, Switzerland, 2006.

54. Deng, J.L. Introduction to Grey system theory. J. Grey Syst. 1989, 1, 1-24.

55. Liu, S.; Lin, Y. Grey System Theory and Application; Springer-Verlag: Berlin/Heidelberg, Germany, 2011.

56. Deng, J. Introduction to grey mathematical resources. J. Grey Syst. 2008, 20, 87-92.

57. Deng, J. Contingency resources stock grey dynamic model. J. Grey Syst. 2011, 23, 113-118.

58. Jia, X.; An, H.; Fang, W.; Sun, X.; Huang, X. How do correlations of crude oil prices co-move? A grey correlation-based wavelet perspective. Energy Econ. 2015, 49, 588-598.

59. Lin, B.; Ouyang, X. A revisit of fossil-fuel subsidies in China: Challenges and opportunities for energy price reform. Energy Convers. Manag. 2014, 82, 124-134.

(C) 2017 by the authors. Licensee MDPI, Basel, Switzerland. This article is an open access article distributed under the terms and conditions of the Creative Commons Attribution (CC BY) license (http:/ / creativecommons.org/licenses/by/4.0/). 